Revista Mexicana de Economía y Finanzas Nueva Época, Vol. 13 No. 4, (2018), pp. 571-584

DOI: http://dx.doi.org/10.21919/remef.v13i4.339

\title{
A Model of the Indirect Effect of Crime on the Demand for Money
}

\author{
Luis Raúl Rodríguez-Reyes ${ }^{1}$
}

Instituto Tecnológico y de Estudios Superiores de Occidente (ITESO)

(Primera recepción: 18/diciembre/2017, última recepción: 23/abril/2018, aceptado: 26/junio/2018)

\section{Abstract}

This paper studies the indirect relation between the demand for money and crime, which emerges from the defensive actions of companies against criminal clients. A theoretical search model is built in which companies trade with criminal clients who consume without paying, allowing the former to hire private security. The model produces two balances in pure strategies. First, if the cost of security is high, companies do not hire private security and the criminal buyers do not carry money. Second, if the cost of security is low, the high demand for money is reestablished. This construct is formalized in a purely theoretical model that generates proposals that can be proven empirically, establishing a future line of research. It should be noted that the indirect effect described has not been discussed in relevant literature. As a result, the existence of an indirect channel between crime and money that emerges from a market externality is demonstrated: the demand of companies for private security endogenously determines the demand for money of the economy.

JEL Classification: D21, D62, D83, E41, K42

Keywords: Crime, Private Security, Demand for Money, Market Externality, Indirect Effect

\section{Un Modelo del Efecto Indirecto del Crimen en la Demanda de Dinero}

\section{Resumen}

Este documento estudia la relación indirecta entre la demanda de dinero y el crimen, la cual emerge de la defensa de empresas en contra de clientes criminales. Se construye un modelo de teoría de búsqueda en el cual empresas comercian con clientes criminales que consumen sin pagar, permitiéndose la contratación de seguridad privada. El modelo produce dos equilibrios en estrategias puras. Primero, si el costo de seguridad es alto, las empresas no contratan seguridad privada y los compradores criminales no portan dinero. Segundo, si el costo de seguridad es bajo, el estado de alta demanda de dinero se reestablece. Este constructo se formaliza en un modelo teórico puro, que genera proposiciones comprobables empíricamente, estableciendo una futura línea de investigación. Es importante notar que el efecto indirecto descrito no se ha discutido en la literatura relevante. Como resultado, se demuestra la existencia de un canal indirecto entre crimen y dinero, que surge de una externalidad de mercado: la demanda de las empresas por seguridad privada determina endógenamente la demanda de dinero de la economía.

Clasificación JEL: D21, D62, D83, E41, K42

Palabras clave: Crimen, Seguridad Privada, Demanda de Dinero, Externalidad de Mercado, Efecto Indirecto

\footnotetext{
${ }^{1}$ Correspondence to: Luis Raúl Rodríguez-Reyes. Departamento de Economía, Administración y Mercadología, Instituto Tecnológico y de Estudios Superiores de Occidente (ITESO). Periférico Sur Manuel Gómez Morín 8585. C.P. 45604 Tlaquepaque, Jalisco, México. E-mail: lrrod72@gmail.com. Tel: +52 (33) 3669 3434. Ext. 3098.
} 
572 REMEF (The Mexican Journal of Economics and Finance)

A Model of the Indirect Effect of Crime on the Demand for Money

\section{Introduction}

Crime against firms can cause disruptions in general economic activity in a region or even a country, and this can occur, not only in crime-ridden-societies, but also in relatively safe countries, with good provision of public security and good record enforcing the rule of law. Early research on this matter was proposed by (Bartel, 1975), who analyzed firm's demand for protection in the U.S. Bartel developed a theoretical model in which criminals may steal products from firms, and cash can be stolen, but only as cash is recognized as another commodity for the financial industry. In her empirical research within the paper, she shows that to determine their demand for protection, firms react to the probability of crime and the size of the loss, and that even if the substitution between public and private security expenditure is theoretically predicted, such relationship does not hold significant with actual data.

Recent empirical research on the subject also supports the negative relationship between crime and private security expenditure. For instance, (Meehan and Benson, 2017) departed from the hypothesis that private security produces positive spillovers on other firms that do not hire it by increasing the expected cost of criminal behavior. Working with a state-level U.S. data in an instrumental variable approach, they found that robbery and property crimes are deterred by the existence of private security. Another example is provided by (Ariel et al., 2017), who measured the efficacy of private policing in deterring crime, using train stations in the southwest of Britain as a part of an intervention under random treatment and control conditions. They employed marginal means and odds ratio analysis to conclude that the presence of uniformed private security guards discourage criminal behavior. There is also evidence of the size of firm's expenditure in private security in emerging economies. For instance, (Amin, 2009) conducted an empirical analysis to determine how small and large businesses are affected by crime. Using data from the World Bank's Enterprise Surveys of 2007, he calculates that, in 14 Latin American countries, $58 \%$ of firms pay $1.3 \%$ of annual sales, on average, for private security. Another instance is provided by (Enamorado et al., 2016), who explored the empirical relationship between income inequality and violent crime rates in Mexican municipalities. In their initial analysis, using the World Bank's Enterprise Surveys of 2012, they compute that 42.8 percent of Mexico's firms spend 2.2 percent of their annual sales in private security measures.

The objective of this research paper is to study the way in which the interaction between the firm's demand for private security and crime indirectly affects the demand for money. To analyze the potential economic disruptions produced by such indirect effect, two assumptions are in place. First, the paper studies criminal activity that does not involve the use money ${ }^{2}$. Second, only property crime is analyzed. The first assumption is imposed to secure that any effect of crime on the demand for money is indirect, while the second is a way to simplify the environment in the model to be developed during the next sections of this paper. That is, from now on, money cannot be stolen or being used as a medium of exchange in shady deals, and crime is defined as the unlawful takeover of produce without the appropriated payment. The hypothesis analyzed here is that this kind of crime, as defined above, disturbs the transactional demand for money in a different way regular cash-related crime does, and from this analysis, new insights can emerge.

To address this question, a search theoretical model to analyze the impact of crime on the demand for money is built, and, the strategic behavior of sellers is analyzed. In order

\footnotetext{
${ }^{2}$ As in Rogoff $(2014,2017)$, the term money is used in this environment as equivalent of paper currency or cash implying anonymity for the holder, and that is why is different from electronic money or credit card money, as with the later, anonymity cannot be guaranteed.
} 
to accomplish such tasks, the model of precautionary demand for money by (Masters and Rodríguez-Reyes, 2005) ${ }^{3}$ is modified in two ways, first, by adding the possibility of criminal behavior as an endogenous buyer's decision, and, second, by establishing an environment with cash only transactions, in which sellers can decide the level of private protection they want to hire.

The paper is organized as follows: In section two, the relevant literature related to the definition of crime and its relationship with cash and other payment media is reviewed. In section three, the basic model of the economy is built; then, in the fourth section, the model is solved when criminal behavior is introduced; the discussion of results and their limits is made in the fifth section, and; finally, in section six some conclusions are drawn.

\section{Literature Review on Crime and Money}

Properties of money that make it useful as a medium of exchange also make it relatable with criminal or underground activities. (Engdahl, 2008) describes its anonymity and high value related to size features as incentives to use money in criminal related interactions, as preferred medium of exchange, or, as subject to theft. These categories in the use of money create a divide between most of the existing literature, as theoretical or empirical research papers depart from one or the other. Moreover, derived from this analysis, a couple assertions can be made. First, if money is the preferred medium of exchange by criminals, or in hidden or shady environments, the relationship between crime levels and the demand for money will be positive, that is, the more criminal, hidden or shady activity in a society, the higher the demand for money would be. Second, when money is subject to theft, there is a negative relationship between crime and monetary holdings. That is, if crime increases, then people prefer to reduce their size of the expected loss in case of a robbery, reducing their monetary holdings.

The first assertion finds overwhelming support in the literature that analyzes the use of the anonymity of money to hide transactions. For instance, in a public policy research body that advocates for the end of cash, Rogoff $(2014,2017)$ argues that the anonymity feature of paper currency is used to hide transactions from governments and regulators, observing that in excess of $50 \%$ of the currency worldwide is used with such aim. ${ }^{4}$ An empirical validation for this proposition is provided by (Immordino and Russo, 2017), who analyzed the relationship between VAT evasion and payment media in Europe. They use a panel technique with data from the European Central Bank Payment Statistics and VAT gap estimations for 25 European countries during the 2000-2012 period, finding a negative relationship between VAT evasion and payment with card (debit or credit). They also find that the use of cash fosters VAT evasion. Moreover, (Ardizzi et al., 2014) developed a measure of the unobserved (cash-settled) economy in Italy, composed by illegal activities (drug dealing and prostitution) and underground economy (tax evasion). In their empirical model, they use a modified currency demand approach and data from the period 2005-2008 to estimate that illegal activities averaged $10.9 \%$ of the Italian GDP in the period of reference, while underground economy averaged $16.5 \%$.

\footnotetext{
${ }^{3}$ In Masters and Rodríguez-Reyes (2005), a market externality, emerging from seller's decision over the acceptance of credit cards, explains the different propensities in the use of credit cards in several countries. In that model, carrying money may be valuable depending on seller's behavior, which is a useful feature for the problem depicted in the current manuscript.

${ }^{4} \operatorname{Rogoff}(2014,2017)$ also argues that large amounts of paper currency hinder central bank's ability to implement a deflation-fighting monetary policy with a large negative interest rate. That is because under such policy people have the incentive to hoard cash. This issue is out of the scope of the current paper, so further literature analysis is going to concentrate on the relationship of crime and money, as a preferred medium of exchange and a subject to theft.
} 
Therefore, to fight tax evasion, underground economy and criminal activity, Rogoff proposes phasing out paper currency, starting with large denomination notes, then smaller notes but small coins and notes, and finally, all of them. Yet, there are some caveats, albeit, Rogoff still calculates more benefits that costs in phasing out paper currency. ${ }^{5}$ Other authors like (McAndrews, 2017) disagree. McAndrews argues that eliminating cash could lead to pernicious changes in the type of crimes being committed as he considers spillovers affecting the type and nature of the complementary and substitute activities in which the money is used. For instance, in the absence of money, criminals could use an honor and secrecy based system of debt to transact, which requires organized crime to be enforced.

Regarding the second assertion, which implies a negative relationship between monetary holdings and crime when money is subject to theft, it is important to notice that it is still under discussion. Some theoretical research supports it. For instance, (Kahn et al., 2005) found that money provides anonymity, as it reduces the risk of theft, compared with the possibility of observable credit transactions. Other example is provided by (Choi, 2011), who showed that an increase in the growth rate of money causes an individual to steal less, since inflation taxes stealing. A similar result is also present in the paper by (He et al., 2008), who proved that some inflation in excess of the Friedman rule reduces the risk associated with cash theft. In their model, individuals can steal money, although bank liabilities are safe in order to generate a consistent environment in which banks have a role as safekeeping and liquidity providers.

Nevertheless, some empirical research challenges the second assertion. It supports a positive money-crime relationship when money is subject to theft. For instance, referring to the theoretical foundations of the Baumol-Tobin model ${ }^{6}$, (Karoubi and Chenavaz, 2015) showed that the higher the incidence of violent crime, i.e., violent theft and street crime, the higher the weekly amount of cash withdrawn, and, they also found a negative correlation between violent theft and the decision of having a paying card. These results may seem counterintuitive, as reduced money holdings seems like the way to diminish the size of expected losses in the event of property crime. However, the authors suggest that instead of it, people identify the number of withdrawals as the risk source, since criminals know ATM locations. Therefore, the public reduces their ATM's visits and increases their monetary holdings via withdrawals, which is consistent with a lower probability of having a payment card. Furthermore, (Armey et al., 2014) empirically studied the relationship between availability of electronic payment technology (per capita POS) -the opposite to transactional demand for paper currency, and economically motivated crimes, such as robbery and burglary. Using OLS, FE and GMM, with data from 70 countries, the authors show the existence of a negative, significant and robust relationship between access to electronic payments and the incidence of economically motivated crimes.

One important issue to be noticed is that, the model proposed in the current manuscript does not belong to any of the two lines of research in the literature already reviewed, as it does not depart from neither of the two transactional uses of money and crime described by (Engdahl, 2008). Here, the basic assumption is that money cannot be subject to theft neither used as a medium of exchange in illegal deals. That is, the only use of money allowed in this model is as a medium of exchange in the acquisition of goods and

\footnotetext{
${ }^{5}$ Costs of implementing Rogoff's plan go from seigniorage income related losses, to high transaction costs, civil liberties issues and the lack of international coordination (Rogoff, 2014).

${ }^{6}$ (Romer, 1986) develops a general-equilibrium, overlapping-generation version of the Baumol-Tobin model -Baumol (1952) and Tobin (1956). It is an inventory-based model of transactional demand for money, in which the optimal path of withdrawals is determined by the tradeoff between the utility derived by consumption, the cost of holding money and the cost of withdrawal.
} 
services. With this assumption in place, the only effect crime is going to have in the demand for money will be indirect.

The current model shares some features with existing literature, but also presents some key differences. For instance, (He et al., 2008) formulation and the one that will be portrayed in the next section of the current manuscript are set in different environments, however, the fact that both models borrow from (Kiyotaki and Wright, 1991) basic framework, makes for similar base case results. In both environments, the value of money decreases with the presence crime. However, there are one crucial difference, which refers to (Engdahl, 2008). In (He et al., 2008), money is related to crime as a subject of theft, while in the model presented in this research paper money is assumed to be safe from theft in order to highlight indirect market effects.

(Mehlum et al., 2002) presented another feature, similar to the work developed in this paper. They analyze the strategic behavior of professionally violent individuals, between plunder or protecting, and the firms' choice between getting protection or not. In their model, as protection against crime rises, the probability of being plundered reduces, as there is a capacity constrain, and violent firms should decide between entering the plunder or protection markets. In our model, developed along next sections, such feature is also present, although, environments and the subject of study are different. In our paper, money is explicitly useful to trade and consume, characterization not present in the (Mehlum et al., 2002) paper.

In the following, the model of precautionary demand for money is developed. Endogenous criminal activity is built into the framework, in a way that allows for the study of the indirect effect of crime on the demand for money and how sellers' strategic behavior determines such relationship.

\section{The Model}

To construct the model presented in this paper, the base framework of precautionary demand for money developed by (Masters and Rodríguez-Reyes, 2005) is modified in two ways, first, by allowing for criminal behavior, and, second, assuming cash only transactions. Therefore, assume that the economy lives for one period and it is composed by a continuum of individuals divided between two groups, buyers and sellers. The total number of buyers is normalized to one and the total of sellers to $\mathrm{N}$.

Sellers cannot consume their own output and buyers are not able to consume money, which the later are endowed with $\mathrm{Y}$ at the beginning of time. To motivate trade in this environment, it is assumed that individuals like what the other group has or can produce. Consequently, buyers and sellers, which randomly meet each other in bilateral meetings, are forced to trade to consume, therefore each seller expect $\eta=\frac{1}{N}$ buyers knocking on his business doors.

At the beginning of time, buyers must decide the amount of money they want to keep in cash, $\mathrm{m}$, in order to consume if they meet a seller. The remaining ( $\mathrm{Y}-\mathrm{m})$ is allocated in an interest-bearing security that yields $r$ at the end of the period.

Buyers have preferences over the size of the only good produced in the economy, which is non-divisible and non-storable commodity, getting utility $\mathrm{u}(\mathrm{s})$ if they consume a quantity $x \geq s$, or zero if they consume a quantity $x<s$. Their preferred size of purchase, $s$, is distributed with a continuous accumulative function $F($.$) , with density f($. and support on $[0, \bar{s}]$. The size of their preference is not known before they met a seller, i.e., think of buyers as people that do not know in the morning how hungry they will be when the reach the store. Notice that the upper bound $\bar{s}$ works as a physical capacity 
constraint for the buyer, so he cannot consume more even if strictly such behavior generate a superior state of wellbeing.

It is assumed for simplicity that sellers can produce, at no cost, any size of the good buyers like, so the possibility of sellers running out of goods at any meeting is ruled out. Sellers also have a linear utility function regarding money; they get a utility q when they acquire q monetary units at a meeting.

The price of the good is normalized to one and bargaining is ruled out once the meeting is in place, so a good size $\mathrm{x}$ costs $\mathrm{x}$ monetary units. That does not mean that prices are fixed but they are exogenous to the model, just as the original (Masters and Rodríguez-Reyes, 2005) formulation, in which the current model is based. So, exogenous price in this environment can be the result of a price-posting game, as the one in (Green and Zhou, 1998) or in (Jafarey and Masters, 2003). The relevant issue here is the ex-ante commitment not to bargain on prices within the meeting and how this is supposed to hold. This is solved by assuming any unspent money has a residual value for the buyer, or similarly, that there is some residual value to the seller for any unwanted merchandise after the meeting.

On this economic environment, buyers have incentives to carry the least amount of money possible (carrying money is costly), however, they must carry some money, otherwise they will not consume. So, they will choose the amount of money that maximize their expected utility, solving

$$
\hat{m} \equiv \operatorname{argmax} m\left\{r(Y-M)+\int_{0}^{m} u(s) d F(s)\right\} .
$$

If certain conditions are met, it is straightforward to prove that an interior equilibrium exists such that

$$
\begin{gathered}
u(\hat{m}) f(\hat{m})-r=0 \\
\text { and } \\
\frac{d \hat{m}}{d(r)}<0, \quad(3)
\end{gathered}
$$

which imply an interior solution to the buyer's problem and that the demand for money reacts negatively to changes in the interest rate. ${ }^{7}$

Under this basic environment, when a buyer meets a seller, he declares his preferred size of purchase and then, if his monetary holdings are higher than the amount needed he proceeds to make a purchase, if his monetary holdings are low, then he walks out the meeting without consuming. Thus, in this model, money is necessary as a medium of exchange, and also carrying it has a precautionary motivation, as buyers do not know their preferred size of purchase when they decide how much money they will carry that morning.

In the next section, this simple setting is enriched with the addition of the possibility of crime and the strategic behavior of sellers.

\footnotetext{
${ }^{7}$ Assumptions on the basic model include: the differentiability of $\mathrm{f}($.$) , that the marginal utility of zero$ money holdings is strictly positive, that the marginal utility of holding the maximum amount of money that is necessary to consume $(\hat{m}=\bar{s})$ is strictly negative, and concavity on equation (1).
} 


\subsection{Modelling Endogenous Crime}

In this section, criminal behavior is introduced into the framework, first as exogenous to the model, and then, it will turn endogenous as the strategic interaction among buyers and sellers becomes more complex. Therefore, it is assumed that buyers are ex-ante divided in two types: a proportion $\lambda$ of them are honest, while the complement $(1-\lambda)$ are criminals, ${ }^{8}$ remaining equal to each other in any other aspect. Under this assumption, the number of criminals in the society is ex-ante exogenous. So, sellers are expected to find $\eta_{1}=\frac{\lambda}{N}$ honest buyers and $\eta_{2}=\frac{(1-\lambda)}{N}$ criminal ones. ${ }^{9}$

Crime is defined as the unlawful expropriation of the commodity produced by the seller, and money is assumed to be safe from theft, and there is no use for money as a medium of exchange in criminal activity, as criminals consume the commodity, i.e., there is not a secondary market for stolen goods. These assumptions may seem counterintuitive or even unrealistic, however, they are used as an instrument to derive important insights from the market externality emerging from the defensive strategies taken by sellers. An alternative to it could be to assume the indivisibility of the good produced and a storage constraint that does not allow agents to carry both, money and goods, as in (Ritter, 1995). This could be enough, as only sellers could be able to steal money from buyers in the current model.

Under this formulation, when a bilateral meeting occurs, if the seller is lucky enough to find an honest buyer, the transaction goes as smooth as it did in the previous section, however, if the seller meets a criminal buyer, he loses his production without receiving payment, as criminal buyers take whatever size of production they like without paying for it. Notice that, up to this point, there are no incentives for criminal buyers to behave in a different way from their ex-ante definition. Being a criminal buyer is quite profitable as they can put all their Y endowment in an interest-bearing account and consume whatever they like, breaking the utility of money as a medium of exchange in the goods market and destroying its precautionary motivation for carrying it.

Nevertheless, as evidence provided on the literature review section shown, sellers normally react to crime by increasing their expenditure in safety measures. Therefore, assume that at the beginning of time sellers must decide if they will contract private protection in order to curb criminal behavior, which will have a one-time cost $\tau>0$. Individual seller's propensity to pay for private security is represented by $\pi \epsilon[0,1]$, and they make their individual decision taking global propensity for all sellers $\Pi \epsilon[0,1]$ as given. This protection service can be understood as a private security guard in the store, cameras, locks, alarms or any other device used to deter dishonest customers, with one important limitation: these measures or items should be inside the store, no to be seen by the buyer before the meeting.

Therefore, criminal buyers know the average propensity for the stores to use some private protection; however, they cannot observe which individual store has paid for it. ${ }^{10}$

\footnotetext{
${ }^{8}$ This way of modeling crime is similar to the one proposed by (He et al, 2008), who also assume that a proportion of the people is a criminal in their basic setting.

${ }^{9}$ It is straightforward to verify that $\eta=\eta_{1}+\eta_{2}$.

${ }^{10} \mathrm{It}$ is assumed that the private protection service available always stops criminal buyers and it is provided in one size only. This assumption can be relaxed by allowing the possibility of a (Becker, 1968) type of crime fighting technology, however, such fallible crime stopping technology does not bring a relevant insight into the discussed problem, as is discussed in next sections.
} 
578 REMEF (The Mexican Journal of Economics and Finance)

A Model of the Indirect Effect of Crime on the Demand for Money

\subsection{Buyer's Problem}

The expected utility of being an honest buyer with cash holdings mh is given by

$$
V_{h b}\left(m_{h}\right)=r\left(Y-m_{h}\right)+\int_{0}^{m_{h}} u(s) d F_{s}(s) .
$$

On the right-hand side, the first part is the expected gain by investing some money at the beginning of time, while the second part is the expected utility of consumption derived from the size of his monetary holdings.

Notice that the honest buyer's expected utility function does not depend on the actual seller's propensity to use private protection, П. For construction, this type of buyer is honest and always pays for his consumption, notwithstanding seller's choice regarding private protection.

Therefore, any honest buyer solves the next problem

$$
\text { máx } m_{h} V_{h b}\left(m_{h}\right)
$$

which displays the same properties as the problem solve in equation (1).

Alternatively, dishonest buyers' expected utility function is given by

$$
V_{d b}\left(m_{d}, \Pi\right)=r\left(Y-m_{d}\right)+\Pi \int_{0}^{m_{d}} u(s) d F(s)+(1-\Pi) \int_{0}^{\bar{s}} u(s) d F(s)
$$

On the right-hand side of this equation, the effect of aggregate sellers' propensity to hire private protection can be seen. In addition to the utils gained for keeping some cash in an interest-bearing asset, also present on equation (4), there is the expected utility of consumption, which reflects whether sellers hired, or not private protection. Notice that the lower is the seller's average propensity of hiring private protection, the higher is dishonest buyers' expected consumption.

If criminal buyers find a seller with private protection, they will consume up to their monetary holdings, $m_{d}$, however, if the find an unprotected seller, they will be able to consume as much as they want, $\bar{s}$.

Therefore, dishonest buyers solve the next problem

$$
\text { máx } m_{d} V_{d b}\left(m_{d}, \Pi\right)
$$

One feature to be noticed is that, even if buyers have been ex ante divided between criminal and honest in an exogenous way, before the meeting takes place, criminal buyers may choose to behave in a lawful way, making the honest behavior an endogenous choice.

\subsection{Seller's Problem}

Sellers' decision framework is simple, they must choose whether to hire private protection to trade and consume money. They should consider how much money the two types of buyer keep liquid and the relative size of honest buyer's mass, $\lambda$. Therefore, seller's expected utility is given by

$$
\begin{gathered}
V_{s}\left(\pi, m_{h}, m_{d}\right)=(1-\pi) \eta_{1} \int_{0}^{m_{h}} s d F(s)+\pi\left[\eta_{1}\left(\int_{0}^{m_{h}} s d F(s)-\tau\right)+\right. \\
\left.\eta_{2}\left(\int_{0}^{m_{d}} s d F(s)-\tau\right)\right]
\end{gathered}
$$

The first term on the right-hand of equation (8) is the income that the seller can expect if he decides not to hire private protection. In this case, if he meets an honest buyer he can sell him his desired size of item up to his monetary holdings. However, if he meets a dishonest buyer, the seller losses its production and cannot consume. The second term depicts the expected flow for the seller if he decides to contract private protection. In this case, sellers can manufacture any size of the commodity preferred by any kind of buyer up to their monetary holdings. Therefore, the seller solves the following problem 
Revista Mexicana de Economía y Finanzas, Vol. 13 No. 4, (2018), pp. 571-584 579

DOI: http://dx.doi.org/10.21919/remef.v13i4.339

máx $\pi V_{s}\left(\pi, m_{h}, m_{d}\right)$

\section{Market Equilibrium}

Definition 1. A market equilibrium is defined as the set $\left\{m_{h}^{*}, m_{d}^{*}, \pi^{*}\right\}$, such that

$$
\begin{gathered}
m_{h}^{*}=\operatorname{argmax} m_{h} V_{h b}\left(m_{h}\right) \\
\mathrm{m}_{d}^{*}=\operatorname{argmax} m_{d} V_{d b}\left(m_{d}, \pi^{*}\right) \\
\pi^{*}=\operatorname{argmax} \pi V_{s}\left(\pi, m_{h}^{*}, m_{d}^{*}\right) .
\end{gathered}
$$

There are two types of equilibrium already identified in the space of $\tau>0$, derived from Definition 1, both in pure strategies. They are defined as the full protection equilibrium $\left(\pi^{*}=1\right)$, in which all sellers choose private protection, and the unprotected equilibrium $\left(\pi^{*}=0\right)$, in which no seller hires private protection, so all of them decide to take their chances in the bilateral meetings.

\subsection{Pure Strategy Equilibria}

Proposition 1. There exists a market equilibrium in pure strategies in the $\tau>$ 0 space, called full protection equilibrium, such that all sellers hire private protection, while monetary holdings for the two types of buyers, honest and dishonest, is positive and equal.

Proof.

For such equilibrium to exist, it is required that $\pi^{*}=1$ for all sellers, that means that the strategy of hiring private protection dominates the one of not doing so, which can be written in terms of equation (8) as follows

$$
\eta_{1}\left(\int_{0}^{m_{h}} s d F(s)-\tau\right)+\eta_{2}\left(\int_{0}^{m_{d}} s d F(s)-\tau\right) \geq \eta_{1} \int_{0}^{m_{h}} s d F(s)
$$

Let $\hat{\tau}$ be defined as the seller's expected differential income of private protection over the unprotected scenario, which can be written as

$$
\hat{\tau} \equiv(1-\lambda) \int_{0}^{m_{d}\left(\pi^{*}=1\right)} s d F(s)
$$

After simple algebraic manipulation and using identity (11), condition (10) can be depicted as follows

$$
\hat{\tau} \geq \tau
$$

That is, for all sellers to choose the full protection strategy the fixed cost of hiring private protection should be lower that the marginal expected income derived from this strategy in opposition to the unprotected strategy.

Since, $m_{d}\left(\pi^{*}=1\right)>0$, if the adequate assumptions are made, in order to $\hat{\tau}$ to be strictly positive it is required that $\lambda<1$, i.e., that not every seller is honest, so if this condition holds, there exists a positive space for $\tau>0$ for which the strategy of hiring private protection strongly dominates the one of not doing so for all sellers. ${ }^{11}$

Regarding monetary holdings, buyers take their decision taking sellers choice as given, in this case $(\Pi=1)$, which implies that every seller hires private protection, so even dishonest buyers have to carry cash in order to consume. Their behavior in this case is not different from honest buyers, therefore, their monetary holdings must be the same. ${ }^{12}$ This is depicted by the equations (4) and (6), which show that the expected utility functions are the same, so in this case

\footnotetext{
${ }^{11}$ Assumptions needed are the same as the ones applied in Section 3 regarding equation (1).

${ }^{12}$ In equilibrium, the endogenous buyer's behavior emerges in this model, so even if buyers are ex ante different, sellers' protection choice make them to elect the way they are going to behave.
} 
580 REMEF (The Mexican Journal of Economics and Finance)

A Model of the Indirect Effect of Crime on the Demand for Money

$$
\hat{m}=m_{h}^{*}=m_{d}^{*}\left(\pi^{*}=1\right)>0
$$

Notice that the assumption made in the basic monetary model regarding $\mathrm{u}($.$) and \mathrm{f}($.$) ,$ ensures the existence of this monetary equilibrium

Proposition 2. There exists a market equilibrium in pure strategies in the $\tau>0$ space, called unprotected equilibrium, such that all sellers do not hire private protection, while monetary holdings for the two types of buyers is different. Honest buyers carry positive monetary holdings while dishonest buyers do not carry any money at all.

Proof.

For such equilibrium to exist, it is required that $\pi^{*}=0$ for all sellers, i.e., that the strategy of do not hire private protection dominates the full private protection one. This can be written as follows

$$
\eta_{1} \int_{0}^{m_{h}} s d F(s) \geq \eta_{1} \int_{0}^{m_{h}} s d F(s)-\eta_{1} \tau+\eta_{2} \int_{0}^{m_{d}} s d F(s)-\eta_{2} \tau
$$

Using identity (11), condition (14) can be expressed as

$$
\tau \geq \hat{\tau}
$$

That is, for all sellers to choose the unprotected strategy, the fixed cost of hiring private protection should be higher that the marginal expected income of doing the opposite.

Concerning their monetary holdings, dishonest buyers do not need to carry any money. A as they know all sellers choose to be unprotected, in a bilateral meeting they can just take the production and go away without making the appropriate payment, thus they maximize their expected utility placing all their endowment into an interest bearing investment at the beginning of time and carry no money, which is evident from equation (6), so $m_{d}^{*}\left(\pi^{*}=0\right)=0$.

For construction, honest buyers do not mind the propensity of sellers paying for private protection, they always carry the same quantity of money as the model without crime, as can be deduced from their respective value functions, so equation (13) becomes

$$
\hat{m}=m_{h}^{*}>m_{d}^{*}\left(\pi^{*}=0\right)=0
$$

One point to notice at this time is that no network externality is present in this model, all the relationship between the level of private protection hired by the sellers and the decision of the amount of money buyers need to carry occurs via the goods market mechanism. This type of market externality is the same as the one depicted in the work by (Masters and Rodríguez-Reyes, 2005). However, in their work, the market externality was active between two competing paying media, credit cards and money, and in the case of the model presented in this article, the externality is present between paying for what buyers consumed and crime, which is only a choice for the ex-ante criminal members of the society.

\subsection{Equilibrium Analysis}

So far, two types of equilibria in pure strategies have been found that are consistent with Definition 1. In their characterization, the key parameter is the cost of hiring private protection, $\tau$, which in its positive space defines two regions of equilibria existence. 
Seller's value function reaches its maximum when the cost of hiring private security is zero, when firms enjoy the advantage of private protection without paying for it. This is equivalent to the value reached when there is no crime in this economy (as in Section 3 ). As private security cost grows into positive space, and $\tau \leq \hat{\tau}$, seller's value function decreases with a slope -. Then, when the cost of private security is higher than the threshold defined by $\hat{\tau}$, sellers decide to go and trade without private protection and their income only comes from their expected meetings with honest buyers.

Regarding the aggregate demand for money in the economy, on one hand, in an unprotected equilibrium, all sellers choose not to hire private protection, which is represented by $\Pi^{*}=0$. As dishonest buyers know their average propensity for sellers to protect themselves, the rational thing to do is not to carry any money at all, so the aggregate demand for money is going to be given by $\lambda \hat{m}$, i.e., only the honest buyers carry money. On the other hand, in a full protection equilibrium, as dishonest buyers know that all sellers are taking measures to protect themselves, they do not have any other option to consume but to behave as honest buyers, i.e., the aggregate amount of money demanded by buyers is given by $\hat{m}$.

\subsection{Some Economic Implications}

The pure strategies equilibria described in this section offer some interesting economic implications. For instance, in a society in which the unprotected equilibrium holds, only honest buyers use money as a medium of exchange, as dishonest buyers do not need it to consume. This implies at least two things.

First, that the level of ex ante honest consumers is crucial to make such economy feasible, in terms of keeping the sellers in the market. Unprotected sellers expected income is represented by the left hand side of equation (14), i.e., $\eta_{1} \int_{0}^{m_{h}} s d F(s)$, which is a growing function of the share of honest buyers in the economy. Notice that not COGS parameter is depicted in there, as the production technology assumed in the model allows sellers to produce freely any size of the good sold. Suppose, without the loss of generality, that a variable cost function is added to sellers' technology. Then, in order to sellers to participate in the market, a sizable share of honest buyers would be required.

Second, there is a space for public policy in this model. The fact that the relatively high cost of private security is the cause of the unprotected equilibrium allows for the discussion of a subsidy scheme. As any tax-funded government activity is exogenous to the model, this is a possible extension of the theoretical construct. Besides any practical consideration, an instance for a potential welfare improving equilibrium would include levying a proportional tax on buyers' savings and with it subsidize the cost of private security for the sellers. This scheme would distribute money from the financial market to the goods market. That may drive the economy to the full protection equilibrium, allowing for a higher expected income for the sellers. Nevertheless, there may exist dynamic inconsistencies not addressed due to static the nature of the model, and the final welfare computation will depend heavily on the value given to model's parameters.

\subsection{Continuous Crime Fighting Technology}

An important point to be notice is that so far in the current model, crime-stopping technology has been assumed to be fully effective and provided to the market in only one size. Thus, seller's expenditure in private security has been discrete. This feature can be relaxed, allowing sellers to choose their optimal quantity of protection, $\psi(E) \in[0,1]$, defining seller's decision variable as the size of expenditure, $E \in[0, \tau]$, which would positively enhance the probability of criminal buyers to be caught, $\psi^{\prime}(E)>0$. 
This formulation is inspired on the one developed by Becker $(1968)^{13}$ and if appropriate assumptions on sellers maximand, described by

$$
\begin{gathered}
\widetilde{V}_{b}=(1-\psi(E)) \eta_{1} \int_{0}^{m_{h}} s d F(s)+\psi(E)\left[\eta_{1}\left(\int_{0}^{m_{h}} s d F(s)-\tau\right)+\right. \\
\left.\eta_{2}\left(\int_{0}^{m_{d}} s d F(s)-\tau\right)\right]
\end{gathered}
$$

are made, an interior expenditure solution would be produced, $E^{*}>0$, with an optimal protection level $\psi\left(E^{*}\right) \in(0,1)$.

Under these conditions, the demand for money for criminal buyers would reach some point between the two pure strategy equilibria already described, such that $m_{d}^{*}(\psi *) \in$ $\left(0, m_{h}^{*}\right)$.

This may seem as a more realistic equilibrium description, as honest buyers will carry the full amount of money needed to consume and dishonest buyers can carry some money but not the full amount, as the probability of being caught is lower than one. However, this would not change the main point made by this paper, that there is a market externality in the goods market that causes an impact on the demand for money even if money is assumed to be safe from theft. That is, with the current model a negative relationship between money and crime can be reached.

\section{Discussion}

There are some points that would demand a further discussion and are matter for future research that will be address to some extend in this section.

First, the current model predicts that in a high crime rate society the marginal use of money will be less than other society in which the crime rate is lower. This seems counterintuitive, but the rationale behind this result is the following: when criminals can rob products or even completely taking over the business of sellers by force and are unopposed, they would not need to carry money, so its value as a medium of exchange fades as much as crime is widespread in a society, while, its value returns when sellers take effective defensive actions. Therefore, the use of money as a medium of exchange and the precautionary demand it in this environment are conditional to the defensive actions of sellers.

However, this can change in a more general model of crime. For instance, when other uses of money regarding crime are incorporated -e.g. as medium of exchange in criminal activities or as subject to theft- is possible that the relationship between money and the level of crime proves to be positive. On such arrangement, the model built in this paper predicts that the level of defensive actions of sellers may produce the existence of nonlinear behavior in such relationship, although, this point is not fully developed in this paper, further than a conjecture and a matter for future empirical research.

Second, in this model there is no explicit difference between contracting private security or paying an extortion to a criminal group. So both interpretations are equivalent in this environment, although, they are ethically different, as paying local criminals to avoid out of town criminals attacking the store is another way to victimize sellers. Considering a way to differentiate such behavior can give another dimension to the study of the interaction between crime, firms and money. However, as this is a strong deviation from the purpose of this research paper, the development of a more complex model that could

\footnotetext{
${ }^{13}$ Modern analysis of crime economics started with (Becker, 1968) seminal analysis, in which the optimal social cost of public policies to fight crime is examined. Main policy variables are expenditure on policing, which has a positive effect on the probability of a criminal of being caught and convicted, and, the size of the punishment.
} 
address this difference would be explored in future research. ${ }^{14}$

Third, in general, crime is defined ad hoc in the literature. Some papers take local police definitions, what they find on the data, or proxy variables. As such, the definition of crime used in the present manuscript is a narrow one, as crime is defined as the possibility a buyer consume a good without paying the price requested in a bilateral random meeting. In this sense, (Kuang, et al., 2017) argue that when discrete crime categories are used to analyze criminal behavior, there is a loss on information that may affect the ability to understand crime. Therefore, they apply text-mining and machine-learning techniques to narratives regarding more than 700 thousand crime events in L.A. They found a clear divide between the categories of property crimes and violent crimes; however, as they analyze subcategories, definitions became fuzzier, defining crime events as a mixture of different components. This establishes a challenge for the research in the matter of money and crime and certainly opens new research lines into the future.

\section{Concluding Remarks}

The main result of this paper is that a negative relationship between the demand for money and level of crime in a society can endogenously arise, cause by a market externality emerging from sellers' choice for protection, without the necessity of a direct relationship between money and the crime itself. Recall that crime is defined as the unlawful expropriation of the commodity produced by the seller, and money is assumed safe from theft and not used as a medium of exchange in shady deals. Therefore, in this environment, the negative relationship between the demand for money and crime does not emerge from the risk of money being an object of theft while being carried, as in other papers in the relevant literature. That represents the main result and contribution of this paper.

In the model, sellers have the ability of protect themselves by paying for private protection (full protected equilibrium), which void the activity of criminal buyers from consuming the commodity without doing the appropriate payment, generating incentives for them to endogenously behave in a lawful way and the higher demand for money state is reached. However, when private security costs are high enough (unprotected equilibrium), this incentive fades, and criminal buyers carry no money at all, for them the use of money as a medium of exchange disappears, and so, firms depend for survival on the ex-ante honest buyers. Therefore, demand for money is affected not only for the solely presence of crime, as literature suggest, but for the reaction of sellers to crime, and crucially, the cost of private protection, $\tau$.

This construct is formalized in a pure theoretical search model, providing two fixed points in pure strategies. Their existence in the positive space of the cost of private protection parameter is mathematically demonstrated and predictions can be empirically verified. Along with the items described in the discussion section, these results lay the ground for future empirical research in this area.

\footnotetext{
${ }^{14}$ For instance, in (Mehlum et al., 2002) framework such difference is not only explicit, but also relevant for their results, however, they do not analyze the problem from a monetary perspective.
} 
584 REMEF (The Mexican Journal of Economics and Finance)

A Model of the Indirect Effect of Crime on the Demand for Money

\section{References}

Amin, M. (2009). Who Suffers More from Crime? SSRN Electronic Journal. Available at http://dx.doi . org/10.2139/ssrn.1508626.

Ariel, B., M. Bland, and A. Sutherland. (2017). 'Lowering the Threshold of Effective Deterrence' - Testing the Effect of Private Security Agents in Public Spaces on Crime: A Randomized Controlled Trial in a Mass Transit System. PLoS, one 12 (12), pp. 1-31.

Ardizzi, G., C. Petraglia, M. Piacenza, and G. Turati. (2014). Measuring the Underground Economy with the Currency Demand Approach: A Reinterpretation of the Methodology, with an Application to Italy. Review of Income and Wealth, 60 (4), pp. 747-772.

Armey, L., J. Lipow, and N. Webb. (2014). The Impact of Electronic Financial Payments on Crime. Information Economics and Policy 29, pp. 46-57.

Bartel, A. (1975). An Analysis of Firm Demand for Protection Against Crime. The Journal of Legal Studies, 4 (2), pp. 443-478.

Baumol, W. (1952). The Transactions Demand for Cash: An Inventory Theoretic Approach. The Quarterly Journal of Economics, 66 (4), pp. 545-556.

Becker, G. (1968). Crime and Punishment: An Economic Approach. Journal of Political Economy, 76 (2), pp. 169-217.

Choi, H. (2011). Money and Crime in a Cash-In-Advance Model. Southern Economic Journal, 77 (3), pp. 652-673.

Enamorado, T., L. López-Calva, C. Rodríguez-Castelán, and H. Winkler. (2016). Income Inequality and Violent Crime: Evidence from Mexico's Drug War. Journal of Development Economics, 120, pp. 128-143.

Engdahl, O. (2008). The Role of Money in Economic Crime. The British Journal of Criminology, 48 (2), pp. 154-170.

Green, E. and R. Zhou. (1998). A Rudimentary Random-Matching Model with Divisible Money and Prices. Journal of Economic Theory, 81 (2), pp. 252-271.

He, P., L. Huang, and R. Wright. (2008). Money, Banking and Monetary Policy. Journal of Monetary Economics, 55 (6), pp. 1013-1024.

Immordino, G., and F. Russo. (2017). Cashless Payments and Tax Evasion. European Journal of Political Economy. In Press.

Jafarey, S. and A. Masters. (2003). Output, Prices, and the Velocity of Money in Search Equilibrium. Journal of Money, Credit, and Banking, 35 (6), pp. 871-888.

Kahn, C., J. McAndrews, and W. Roberds. (2005). Money is Privacy. International Economic Review, 46 (2), pp. 377-399.

Karoubi, B. and R. Chenavaz. (2015). Does Crime Influence the Payment Decisions of Consumers?. Journal of Applied Business Research, 31 (5), pp. 1709-1718.

Kiyotaki, N. and R. Wright. (1991). A Contribution to the Pure Theory of Money. Journal of Economic Theory, 53 (2), pp. 215-235.

Kuang, D, P. Brantingham, and A. Bertozzi. (2017). Crime Topic Modeling. Crime Science 6 (1), pp. 12-32.

Masters, A. and L. R. Rodríguez-Reyes. (2005). Endogenous Credit-Card Acceptance in a Model of Precautionary Demand for Money. Oxford Economic Papers, 57 (1), pp. 157-168.

McAndrews, J. (2017). The Case for Cash. ADBI Working Paper Series 679. Asian Development Bank Institute.

Meehan, B. and B. Benson. (2017). Does Private Security Affect Crime?: A Test Using State Regulations as Instruments, Applied Economics, 49 (48), pp. 4911-4924.

Mehlum, H., K. Moene, and R. Torvik. (2002). Plunder Protection Inc. Journal of Peace Research, 39 (4), pp. 447-459.

Ritter, J. (1995). The Transition from Barter to Fiat Money. The American Economic Review, 85 (1), pp. 134-149.

Rogoff, K. (2014). Costs and Benefits to Phasing out Paper Currency. NBER Macroeconomics Annual 29 (1), pp. 445-456.

Rogoff, K. (2017). The Curse of Cash: How Large-Denomination Bills Aid Crime and Tax Evasion and Constrain Monetary Policy, 1st ed., Princeton University Press, Princeton, N.J.

Romer, D. (1986). A Simple General Equilibrium Version of the Baumol-Tobin Model. The Quarterly Journal of Economics 101 (4), pp. 663-685.

Tobin, J. (1956). The Interest-Elasticity of Transactions Demand for Cash. The Review of Economics and Statistics 38 (3), pp. 241-247. 